\title{
Effect of process conditions on bio-oil obtained through continuous hydrothermal liquefaction of Scenedesmus sp. microalgae
}

Mariusz Wądrzyk ${ }^{\mathrm{a}, \mathrm{b}, *}$, Rafał Janus ${ }^{\mathrm{a}, \mathrm{b}}$, Mathijs P. Vos ${ }^{\mathrm{c}}$, Derk Willem Frederik Brilman ${ }^{\mathrm{c}}$

${ }^{a}$ AGH University of Science and Technology, Faculty of Energy and Fuels, al. A. Mickiewicza 30, 30-059 Krakow, Poland

$\underline{b}$ AGH University of Science and Technology, AGH Centre of Energy, ul. Czarnowiejska 36, 30-054 Krakow, Poland

${ }^{c}$ University of Twente, Sustainable Process Technology Group (SPT), Faculty of Science and Technology, PO Box 217, 7500 AE Enschede, The Netherlands

*Corresponding author. E-mail: wadrzyk@agh.edu.pl; Tel. (+48) (12) 617-38-90

\section{Abstract}

Hydrothermal liquefaction of biomass in near-/supercritical water has attracted great attention in recent years. Although this technology seems to be promising for transformation of microalgal biomass, the information on the impact of feedstock and processing variables of continuous hydrothermal liquefaction on the properties of bio-oil provided in previous literature is scarce. Herein, the low-lipid Scenedesmus sp. biomass has been transformed to bio-oils through continuous hydrothermal liquefaction under various process conditions. The influence of temperature and residence time on bio-oil characteristic was discussed based on characterization by IR, GC-MS and gel permeation chromatography. The relative degree of branching of carbon chain of bio-oils components was estimated based on deconvolution of methyl and methylene IR absorption bands. The presumptive pathways of the reactions have been postulated. Finally, it was found that the parameters of bio-oil may be tailored by adjustment of processing variables, however, possible subsequent/parallel effects must be considered while designing the process.

\section{Keywords}

Scenedesmus sp., microalgae, continuous hydrothermal liquefaction, bio-oil, analysis, chemical composition 


\section{Introduction}

The rapidly growing demand for energy and the necessity of diversification of its supplies leads to a constant search for new alternative sources of energy [1]. Therefore, various types of conversion methods of renewable raw materials and wastes are the subject of extensive research of many scientific groups worldwide, as clearly evidenced by the vast increase in a number of publications concerning bio-oil (whether or not from microalgae). The recently published review papers summarizing the state-of-the-art in this field are particularly valuable [2-7]. Among the numerous advanced technologies of production of bio-oil from microalgal biomass, the process of hydrothermal liquefaction (HTL) appears to be very promising. The HTL process consists in a chemical conversion of biomass components employing the specific properties of near-critical water used as a reaction medium. Therefore, the feed does not require energy-consuming drying prior to conversion.

Water under its sub- and supercritical conditions exhibits certain unique properties. Because of disruption of the hydrogen bonds, some interesting and desirable properties appear: (i) the polarity decreases resulting in an almost unlimited miscibility of water with non-polar organics; (ii) the dielectric constant decreases; (iii) the density, viscosity and surface tension drop rapidly near the critical state; (iv) the self-ionization constant increases with temperature, up to about $350{ }^{\circ} \mathrm{C}$ and then decreases suddenly down to ca. $500{ }^{\circ} \mathrm{C}$ by a five orders of magnitude [8-10]. As a consequence, the conversion of biomass toward bio-oil in nearcritical water is favoured due to its: (i) ability to sustain free-radical/ionic reactions above/below the critical point; (ii) promotion of single phase reactions; (iii) reduced mass transfer limitations and increased reaction rate; (iv) lack of phase transition causing accelerated heat recovery; (v) possibility of separation of particular products by adjusting pressure/temperature; (vi) possibility of engagement of the intensively formed $\mathrm{OH}^{-}$and $\mathrm{H}_{3} \mathrm{O}^{+}$ ions in the role of an acid or base catalyst. 
There are numerous publications on the impact of nature of raw materials as well as the effect of process conditions on the yield of produced bio-oil [11-14]. The former research have shown that the type and content of the main biochemical components, i.e. proteins, lipids and carbohydrates in the raw biomass, have an essential impact on the composition of the ultimate bio-oil $[5,6,15]$. Furthermore, the properties of the HTL bio-oil are strongly affected also by processing conditions i.e. temperature $[5,12,13,16-19]$, heating rate $[16,17,20]$, reaction time [13,16-18], biomass loading [5,18,19] , presence and type of catalyst [5,16,18, 19,21,22], procedure of product recovery [16,23,24], among which temperature and reaction time exhibit profound impact. Obviously, the temperature and reaction time are fundamental factors in terms of the economy of the whole technology. Bio-oil as a complex mixture of plenty valuable chemicals may find applications in various industries. Thus, identification of the target application of bio-oil components is a key factor when designing the conversion process parameters. Despite the progress that has been made in recent years in the development of the technologies of hydrothermal liquefaction of microalgae, many issues remain still unclear and require further research. Comprehensive data reported in the literature, in spite of its richness in some aspects, are still fragmentary in others (e.g. comparison of processes conducted in various HTL operating mode and in analyses applied). At this point in time, HTL cannot be considered as a mature technology and its development still benefits from exploring the effects of process conditions (especially for continuous processing) and analyzing in more detail the products produced. The present study aims to contribute to the technology development by expanding the underlying basis of knowledge and data.

Nowadays, the wide majority of published papers refer to batch HTL tests, while in terms of technological development point, the continuous mode is more desirable. Thus, more efforts should be paid to compare the trends observed and results obtained in the batch autoclaves of 
varying types and sizes used by the various research groups with results obtained from a set of various, continuous-type setups. However, it has to be emphasized that although a majority of the studies on algae HTL have been focused on batch processing, it is clearly evidenced that recently this trend is changing towards continuous-mode processes performed in sub- and supercritical water. This in turn proves the demand for evaluation of possibility for scaling-up the technology [12,25-28].

The main aim of present research was to investigate the effect of process variables (i.e. temperature and residence time) during continuous hydrothermal liquefaction (cHTL) of microalgae on the composition of the ultimate bio-oil and, with this, contribute to the building of a dataset for comparison of batch experiments to continuous processing to enable a more reliable scale-up from lab-scale batch results. The studied bio-oil was obtained by continuous HTL process performed with Scenedesmus sp. microalgae biomass-containing slurry at temperatures of $250-350{ }^{\circ} \mathrm{C}$ and residence time of $7-30 \mathrm{~min}$. The chemical composition of the product was analyzed by means of mid-infrared spectroscopy (FT-IR), gel permeation chromatography (GPC) and gas chromatography coupled to mass spectrometry (GC-MS). Finally, where possible, the likely reaction pathways have been postulated.

\section{Materials and methods}

\subsection{Feedstock}

The low-lipid Scenedesmus sp. microalgae sample was produced by Ingrepro B.V. (The Netherlands). These algae were grown autotrophically in an open pond under continuous stirring with paddle wheels. The sample in the form of slurry containing ca. 5.65 wt. \% of biomass was stored, as received, in $5 \mathrm{~L}$ sealed vessels kept in refrigerator at $4{ }^{\circ} \mathrm{C}$. The feedstock was subjected to continuous hydrothermal liquefaction without any pretreatment or concentration changes. Using this feed concentration is within the range of interest [16] and results are expected to be representative for higher feed concentrations [13]. 
The choice of Scenedesmus sp. was dictated by its beneficial features in view of the feasibility of the HTL process in a large scale toward bio-oil production. There are several advantages of this strain, as follows: Scenedesmus sp. belongs to the most vigorously growing green microalgae that outcompete with most other algal species under high nutrient containing media, i.e. wastewater. The most relevant advantages of this strain are: (i) tolerance to high temperature (up to $40^{\circ} \mathrm{C}$ ), (ii) resistance to aeration and impulsion of centrifugal pumps, (iii) tolerance to wide range of $\mathrm{pH}$ (5 up to 10), (iv) lack of sensitivity for the use of nitrates, ammonia or urea as nitrogen source (e.g. from effluents), (v) possibility of outdoor production (using both the systems, open reservoir and closed photobioreactors), (vi) easy scale-up of production [29].

\subsection{Experimental setup}

The schematic draw of the setup used for cHTL experiments is shown in Fig. 1. The main component of the setup was the stainless steel tubular reactor of the dimensions of $3 \mathrm{~mm}$ (inner diameter), $6 \mathrm{~mm}$ (outer diameter) and length of $5.5 \mathrm{~m}$. In order to reduce the size, the reactor was coiled in 22 rings. Heating was provided by a vertical tubular electric furnace equipped with fluidized sand bed (S60 Filcom sand; particle size: $0.1-0.3 \mathrm{~mm}$ ), in which the coiled reactor was immersed. Four controlling thermocouples were placed in the heating section: three on the walls of the reactor (in the top, middle of the height and in the bottom) and one directly in the fluidized bed. From the reactor dimensions and flow rate applied an overall heat transfer coefficient of $200-250 \mathrm{~W} \cdot \mathrm{m}^{-2} \mathrm{~K}^{-1}$ and an (initial) heating rate of $40 \mathrm{~K} \mathrm{~s}^{-1}$ is calculated.

The pressure in the reactor was adjusted by a back pressure valve. The pressure inside the reactor coil was measured in the inlet and outlet of the conversion unit. The maximum permissible pressure for the used setup was 500 bar. The cHTL products were cooled by the water cooler and collected in respective product collectors. Gas samples were periodically 
taken for GC analysis in the outlet of the reactor. The experimental setup was equipped with a control panel and Picolog software for monitoring and recording of the operating parameters. The collected data included operating pressure, temperature at various locations along the reactor wall and biomass fed to the system.

The experimental setup was working in a stop-and-go mode. The reaction time was calculated as a function of the volume of coil space, the temperature of process and inlet volumetric flow rate. The latter one was controlled by setting frequency and stroke length of the pump. The reaction time was measured from the moment of the input of feedstock into reactor coil, i.e. the heating time was included. The operating pressure was always kept around 50-100 bar above water vapor pressure at given temperature to maintain a safety limit in a case of possible clogging and to warrant that the water remains in a liquid state. The exemplary pressure and temperature profiles throughout the experiments run are depicted in supplementary information section (cf. Appendix A). The experiments were carried out at temperature of 250,300 and $350^{\circ} \mathrm{C}$, while the residence time equaled 7,17 and $30 \mathrm{~min}$. The latter residence time is the maximum possible with the available setup and, from there, the residence time is varied by approximately a factor two and four to cover a broad range and to enable comparison with (batch) experiments.

Prior to start each cHTL run, an initial test of setup stability was carried out, at least for three times for the average residence time, which was found to be (more than-) sufficient. The actual tests as reported here were started after checking the stability of process conditions and ruling out any leaks and line blockages. For each data point, the whole experiment, including startup, was repeated at least twice. After every test and before shutting down operation, the apparatus has been cleaned by purging with distilled water until all residual HTL products were washed out.

\subsection{Product separation and yield calculation methodology}


In order to isolate the bio-oil from as-received reaction mixture, extraction with dichloromethane (DCM; Sigma Aldrich 99.9\%) was employed, according to the method reported elsewhere [30]. Solvent extraction supported product recovery was chosen as a most suitable because of the small scale of operation and for the sake of a better comparison with batch experiments. Ultimately, four following products were isolated from the reaction mixture: (i) bio-oil; (ii) water phase containing dissolved organics; (iii) volatile phase; and (iv) solid residue. In our approach, the bio-oil was defined as the mixture of DCM-soluble organics, recovered after filtration and removal of the extraction medium. The content of water soluble organics was calculated as the mass of the residue after removal of water minus ash content (determined by annealing at $550{ }^{\circ} \mathrm{C}$ for $5 \mathrm{~h}$ ). The yield of solid product was determined as a mass of solid residue obtained by the filtration of the DCM-extracted bio-oil. The filtrate cake was dried at $105{ }^{\circ} \mathrm{C}$ for $24 \mathrm{~h}$. The yield of gaseous (non-condensable) products evolved during cHTL process was computed based on the gas composition according to the ideal gas law (determined by GC analysis) and the volume of the gas released during the process measured at room temperature $\left(20^{\circ} \mathrm{C}\right)$. The gas composition and description method of GC analysis was presented in supplementary section [cf. Appendix B]. All the cHTL products yields discussed in this paper were calculated on a dry and ash-free matter (daf). The yields of the ultimate products have been calculated as a wt. \% contributions with respect to the mass of dry and ash free matter of starting biomass. The product yields for the chosen reaction parameters are presented as an average values of three repetitions (three samples analyzed) along with the standard deviations. Mass balance closure was always satisfactory (>95\%). Carbon mass balance closure for performed tests varied in the range of 80-100 wt. \%., with deficiencies in the carbon mass balance mainly due to the formation of solid deposits onto the internal surfaces of the unit. 


\subsection{Bio-oil analysis methods}

Elemental analysis $(\mathrm{C}, \mathrm{H}, \mathrm{N})$ of the studied feedstock and final products was carried out using Thermo Scientific Flash 2000 apparatus. The oxygen content was determined by difference. Each run was repeated twice. Higher heating values (HHV) of raw algae biomass and ultimate bio-oils were calculated according to Boie’s formula (eq.1).

$$
\mathrm{HHV}_{\mathrm{s}, \text { Boie }}=0.3516 \cdot \mathrm{C}+1.16225 \cdot \mathrm{H}-0.1109 \cdot \mathrm{O}+0.0628 \cdot \mathrm{N} \quad[\mathrm{MJ} / \mathrm{kg}] \text {, }
$$

where $\mathrm{H}, \mathrm{C}, \mathrm{O}, \mathrm{N}$ refer to hydrogen, carbon, oxygen and nitrogen contents, respectively (wt. \%).

The total lipid content in microalgae biomass was analyzed by Soxhlet extraction using hexane (Avantor PM, 99\%). The protein content was estimated based on the nitrogen content multiplied by the Jones’ conventional factor (6.25) [31]. The contents of carbohydrates and cell wall substances were calculated as the difference (total organic mass - lipid content protein content).

The composition of prepared bio-oils was investigated by means of mid-infrared Fourier transform spectroscopy. The spectra were collected on a FTIR Tensor 27 (Bruker) spectrometer equipped with attenuated total reflectance device (ATR) and DTGS detector. Ten spectra were recorded at a wavenumber region of $650-4000 \mathrm{~cm}^{-1}$. The samples were analyzed as-received, without any preparation. In order to enable a comparative analysis of the bio-oils, the spectra were normalized using Kubelka-Munk approach.

The determination of the molecular mass distribution of the bio-oils was carried out using an Agilent 1200 series HPLC system equipped with three GPC PLgel MIXED-E columns (diameter of $3 \mu \mathrm{m}$ ) coupled in outlet-to-inlet cascade. The GPC oven was maintained at $40{ }^{\circ} \mathrm{C}$, the constant flow of eluent (tetrahydrofuran; THF for HPLC; $\geq 99.9 \%$; Sigma Aldrich) was fixed at $1 \mathrm{~mL} / \mathrm{min}$. The system was equipped with the refractive index detector (RID) and the variable wavelength detector (VWD). Prior to the analysis, the sample was prepared as 
follows: amount of ca. $50 \mathrm{mg}$ of bio-oil was dissolved in $5.0 \mathrm{~mL}$ of THF and then filtered through a PTFE $0.2 \mu \mathrm{m}$ syringe filter (Whatman) to remove solid impurities. The choice of THF as a suitable solvent for GPC analysis is justified in view of the recent research by Harman-Ware and Ferrell III [32]. Calibration of the GPC was performed for reference compounds of a molar masses ranging between 169 and $29510 \mathrm{~g} \cdot \mathrm{mol}^{-1}$. As the GPC technique is highly sensitive to the fluctuations in the measurement conditions, the sample were prepared with special care and all the analysis parameters were strictly adhered to. The composition of volatile products of cHTL was analyzed using gas chromatography coupled to mass spectrometry (GC-MS). The analyses were performed on GC-MS Agilent type GC 7890A equipped with a MS 5975C mass spectrometer. The Agilent DB-17 capillary column of dimensions of $60 \mathrm{~m} \times 0.25 \mathrm{~mm} \times 0.25 \mu \mathrm{m}$ was used. Helium of a grade of 6.0 was used as a carrier gas at a flow rate of $2.0 \mathrm{~mL} / \mathrm{min}$. The bio-oil samples were prepared as a 5 wt. \% solutions in acetone (Sigma Aldrich; HPLC grade). Prior to injection to GC, the sample was filtered through a $0.2 \mu \mathrm{m}$ PTFE syringe filter (Whatman). The volume of $1 \mu \mathrm{L}$ of the prepared sample was injected to the GC (injector temperature of $250^{\circ} \mathrm{C}$ ). The analysis was performed at a split ratio of 20:1. The oven temperature was initially set to $45^{\circ} \mathrm{C}$ with a hold time of $4 \mathrm{~min}$, then increased at $3{ }^{\circ} \mathrm{C} / \mathrm{min}$ until $280{ }^{\circ} \mathrm{C}$ and held constant for $20 \mathrm{~min}$. The ion source temperature was $230{ }^{\circ} \mathrm{C}$, electron ionization was set at $70 \mathrm{eV}$, and spectra were scanned from 28-500 m/z. The obtained MS spectra were interpreted based on the reference MS library (chemical base G1034C). The threshold for the match factor calculated based on electronic library search routines was equal to $75 \%$. Each analysis was repeated twice and results were calculated as a mean value if the relative standard deviation was below $10 \%$. The contributions of detected compounds/group of compounds were computed relatively as a ratio of peak area of compounds to the summary peak area of all detected compounds. Peak area was determined in the total ion mode. 


\section{Results and discussion}

\subsection{Feedstock composition}

The biochemical composition as well as proximate and ultimate analysis results are listed in Table 1 . The proximate analysis of the studied biomass revealed 48.1 wt. \% of fiber and carbohydrates, 46.3 wt. \% of proteins and 5.6 wt. \% of lipids (dry, ash-free matter, daf.). Relatively high content of nitrogen (7.4 wt. \%) originates from high content of protein in the raw biomass while the high content of fibers and carbohydrates is clearly reflected in the high content of oxygen (27.9 wt. \%). The ultimate elemental analysis revealed the low content of sulfur (0.4 wt. \%), what indicates a negligible contribution of sulfur-containing amino acids in the protein component as well as other S-containing compounds (i.e. dimethylsulfoniopropioniate as algae metabolite [33]). The $\mathrm{pH}$ of the slurry measured at $20.5^{\circ} \mathrm{C}$ was 6.8 (METROHM $780 \mathrm{pH}$ meter).

\subsection{Bio-oil yield and its elemental composition}

For all process conditions tested in the present work, the bio-oil yields varied in a range of ca. 20-36 wt. \% in relation to dry ash free biomass. This range is comparable to previously reported data on the batch experiments conducted with microalgae comprising bio-oil recovery by DCM extraction, ranging commonly within ca. 30-50 wt. \% [13,14,19,30,34,35]. The highest bio-oil yield was noted for the highest process temperature $\left(350^{\circ} \mathrm{C}\right)$ and the longest reaction time (30 min). In general, it can be inferred that more severe conditions led to higher yields of bio-oil and volatile (non-condensable) products. At less severe conditions, more solid residue and water soluble organics were observed. It is noteworthy to mention that temperature had a more pronounced impact on the change of product yields distribution than reaction time. The product yields distributions for the chosen bio-oil samples as the boundary cases (i.e. after 7 minutes at $250{ }^{\circ} \mathrm{C}$ of process and 30 min at $350{ }^{\circ} \mathrm{C}$ ), are depicted in Fig. 2 . 
The resultant bio-oils were dark and viscous liquids with an appearance similar to crude petroleum or heavy tar (cf. Fig. 2, insets). The change of process temperature toward higher values resulted in a gradual decrease in viscosity. In order to deepen the investigation on the impact of process conditions on the nature of product, the elemental analysis of resultant biooils was carried out. The results are compiled in the tables inserted in Fig. 2. The obtained results are in close agreement with those reported elsewhere [15,36,37], however a close inspection of the results allowed us to formulate certain interesting conclusions. The increase in process temperature by $100{ }^{\circ} \mathrm{C}$ caused the carbon content in the resultant oil to rise from 66.1 to 72.5 wt. \%, while the hydrogen content remained at an approximately constant level of 8.5-9.0 wt. \%. Interestingly, the hydrothermal liquefaction of Scendesmus sp. at temperatures closer to the critical point (i.e. $350{ }^{\circ} \mathrm{C}$ ) caused a considerable drop in the oxygen content by ca. $8 \%$ (i.e. from 20.8 to 12.8 wt. \%.), which is especially desirable in terms of energetic value of the product. The more pronounced deoxygenation of bio-oil at higher temperature is in line with observations in batch reactors discussed in previous works on similar microalgal feed $[30,38]$. It is also pertinent to mention the relatively high content of nitrogen

(i.e. 4.5 wt. $\%$ at $250{ }^{\circ} \mathrm{C}$ ) and its slight increase by $1.0 \mathrm{wt} . \%$ at higher temperatures. This is desirable from the point of lubricity of such biocomponent, but unacceptable due to the $\mathrm{NO}_{\mathrm{x}}$ emission during combustion. For fuel applications it is especially noteworthy and advantageous, that the higher heating values (HHV) calculated for the studied bio-oils were more than twice higher compared to raw biomass (cf. Table 1). Apparently, the increase in HHV noted at higher processing temperatures was the result of deeper deoxygenation, as was mentioned above.

\subsection{FT-IR}

The FT-IR spectra collected for the bio-oils obtained at different time and temperature brought some deeper insight into the issue of elucidation of the influence of these parameters 
of cHTL on the composition of the resulting bio-oil (Fig. 3A). Obviously, it should be noted that the comparative analysis of these spectra is not intended to be an absolute (i.e. quantitative) analysis of their composition. The transformation of ATR spectra to KubelkaMunk units allowed us only to calculate the relative differences in the intensity of respective bands. Thus, it provides some interesting information concerning the relative changes of the content of a certain groups of compounds as a function of process variables.

The behavior of the collected spectra (position and shape of the absorption bands) exhibits their similarity in term of qualitative composition, but the differences in the intensities of particular modes demonstrate apparently a considerable influence of time and temperature of cHTL on the relative contribution of various groups of organics. The characteristic set of absorption bands clearly proves the presence of aliphatic compounds (paraffins, olefins), aliphatic- and aromatic-derived oxygenates (alcohols, ketones, phenols), aromatic hydrocarbons, nitrogen compounds (amides and amines) as well as heterocyclic compounds (mainly those containing $\mathrm{O}$ and $\mathrm{N}$ ). The close inspection of changes in the spectra allows to formulate the following conclusions:

1. The broad band at $3000-3500 \mathrm{~cm}^{-1}$, ascribed to -OH stretching mode in alcohols and phenols, in case of liquefaction at $250^{\circ} \mathrm{C}$ exhibits increase in the intensity with the rising time while for the bio-oils produced at $350^{\circ} \mathrm{C}$ the opposite effect is observed. This may be assigned to a slight fragmentation of biomass components at the lower temperature without degradation of oxygen-containing moieties. At the higher temperature the effect of dehydration of the intermediates, causing in turn the depletion of the oxygenates content in the resultant product, is more pronounced.

2. Similar scenario could be observed for the absorption bands at $1775-1650 \mathrm{~cm}^{-1}$ and 1490 $\mathrm{cm}^{-1}$, ascribed to carbonyl $\mathrm{C}=\mathrm{O}$ stretching vibrations and unsaturated $\mathrm{C}=\mathrm{C}$ bonds, respectively. The plausible explanation is that at $250{ }^{\circ} \mathrm{C}$ may occur the effect of 
fragmentation of biomass components with elimination of unsaturated species. The temperature of $350{ }^{\circ} \mathrm{C}$ favors deeper fragmentation but, on the other hand, it also can cause the repolymerization of the compounds having highly-reactive $\pi$ bonds. The lower content of aromatic compounds in this case may be due to the scissions of the polymeric species and/or ring-opening reactions.

3. The low temperature and short time of liquefaction favors the formation of the polycyclic aromatic hydrocarbons which is manifested by the presence of absorption mode centered at $3010 \mathrm{~cm}^{-1}$. At higher temperatures this band vanishes due to the deeper fragmentation of polymeric species present in raw material.

The Lorentzian deconvolution of the bands present in the region of ca. $2750-3050 \mathrm{~cm}^{-1}$ have been formerly proposed to determine the relative length of carbon chains in crude hydrocarbon oil $[39,40]$. Herein, we employed this approach to evaluate the relative changes in the composition of bio-oils with varying time and temperature of the process. The analysis of the spectra in the region of ca. 2750-3050 $\mathrm{cm}^{-1}$ (aliphatic hydrocarbon length) has been additionally extended by the deconvolution of the region of $1600-1750 \mathrm{~cm}^{-1}$ to evaluate the nature and relative concentration of various carbonyl compounds (cf. Fig. 3B). Both regions were deconvoluted using Lorentzian function. In the region of $2750-3050 \mathrm{~cm}^{-1}$ four partially overlapping bands are observed as follows: $2854 \mathrm{~cm}^{-1}$ - symmetric stretching vibrations of $\mathrm{CH}_{2}$ ( $v \mathrm{CH}_{2}$ sym.); $2870 \mathrm{~cm}^{-1}$ - symmetric stretching vibrations of $\mathrm{CH}_{3}\left(\mathrm{vCH}_{3} \mathrm{sym}.\right) ; 2923$ $\mathrm{cm}^{-1}$ - asymmetric stretching vibrations of $\mathrm{CH}_{2}\left(\mathrm{vCH}_{2}\right.$ asym.) and $2955 \mathrm{~cm}^{-1}$ - asymmetric stretching vibrations of $\mathrm{CH}_{3}\left(\mathrm{vCH}_{3}\right.$ asym.).

The relative intensities of $\mathrm{CH}_{2}$ and $\mathrm{CH}_{3}$ asymmetric stretching vibrations bands and corresponding $\mathrm{C}=\mathrm{O} / \mathrm{CH}_{2}$ ratios are displayed in Fig. 3C and 3C', respectively. The calculation of the relative intensities of $v \mathrm{CH}_{2}$ asym. $/ \mathrm{CCH}_{3}$ asym. allows to estimate the relative ratio of methylene-to-methyl groups. Higher ratio of $\mathrm{I}_{\mathrm{CH} 2} / \mathrm{I}_{\mathrm{CH} 3}$ indicates higher content of $\mathrm{CH}_{2}$ groups 
and therefore the presence of long-chain and/or more complex aliphatic structures [39,40]. Furthermore, the ratio $\mathrm{I}_{\mathrm{CH} 2} / \mathrm{I}_{\mathrm{CH} 3}$ provides information about the degree of terminal substitution. As can be seen the increase in reaction time at $250{ }^{\circ} \mathrm{C}$ (cf. Fig. 3C) entails the depolymerization trend of high molecular compounds (a gradual decrease in the ratio $\mathrm{I}_{\mathrm{CH} 2} / \mathrm{I}_{\mathrm{CH} 3}$ ). The opposite observations were noticed at more elevated temperatures. This effect could be ascribed to the re-polymerization of intermediates, especially more pronounced at $350{ }^{\circ} \mathrm{C}$ than at $300{ }^{\circ} \mathrm{C}$. This is in full compliance with GC-MS results (cf. Table C1, Appendix C; for instance the increase in 1-eicosane content with growing temperature was noticed). Furthermore, it is also coherent with GPC results where shortening of the tail of the distribution can be seen with increasing reaction times at $250{ }^{\circ} \mathrm{C}$, as well as, more homogeneous molecular weight distribution curve. At $350{ }^{\circ} \mathrm{C}$, less pronounced trend was observed, but the slight increase in contribution of heaviest compounds with prolonged reaction time can be noticed (cf. Fig. 4B, B'). Importantly, based on GPC results, one may infer that the increase in process temperature exhibits deeper impact on the degree of the decomposition is more pronounced for shorter reaction times than for longer (cf. Fig. 4 A, A').

In the wavenumber region of $1600-1750 \mathrm{~cm}^{-1}$ an intensive and sharp band of $\mathrm{C}=\mathrm{O}$ stretching vibrations is observed. Obviously, this region spans also the absorption modes of aromatic ring but taking into account relatively low content of aromatics as revealed the GC-MS analysis (cf. Fig. 5) one may infer that these absorption bands will not affect remarkably the shape of carbonyl bands. The low content aromatics is additionally reflected in a negligible intensity of aromatic ring vibration in the region $3050-3100 \mathrm{~cm}^{-1}$ (cf. Fig. 3A, A', B). In contrast, considerable total amount of aromatics (also phenols and indoles) revealed by GCMS was found. Naturally, one should keep in mind that the differences in the interpretation of aromatics content based on FT-IR and GC-MS data arises from the differences in the part of 
the sample amenable for analysis (only ca. 37\% of bio-oil components are amenable to GCMS). Since the position of $\mathrm{C}=\mathrm{O}$ band varies depending on the chemical surrounding (i.e. presence of adjacent electron donating/accepting groups), one can draw conclusions on the relative contents of various types of carbonyl compounds. The deconvolution of the discussed region gave four bands with the maxima centered at 1651, 1671, 1702 and $1734 \mathrm{~cm}^{-1}$. At the temperature of $250{ }^{\circ} \mathrm{C}$ the intensity of absorption bands at $1651 \mathrm{~cm}^{-1}$ and $1671 \mathrm{~cm}^{-1}$ increases with rising time while at $350{ }^{\circ} \mathrm{C}$ the contrary effect is observed. It may be inferred that the lower temperatures and longer times favor the formation of $\alpha, \beta$-unsaturated ketones, aromatic ketones and amides. Regardless the temperature, the band at $1702 \mathrm{~cm}^{-1}$ decreases with increase in the residence time. This means that the content of carboxylic acids and/or esters does not primarily depend on temperature, but longer time causes drop in their content. In fact, from GC-MS analysis (cf. Fig. 5), the total ketones share is higher at $300^{\circ} \mathrm{C}$ than at the lowest temperature but at $350^{\circ} \mathrm{C}$ it was slightly lower compared to $300^{\circ} \mathrm{C}$. In contrast, the increase in process temperature resulted in higher content of aliphatic hydrocarbons what could affect the relative ratios calculated based on FT-IR. The absorption band at $1734 \mathrm{~cm}^{-1}$ is observed only for the sample prepared at $250{ }^{\circ} \mathrm{C}$ for $7 \mathrm{~min}$. This band is assigned to esters and aldehydes. The lack of this band in case of longer times and higher temperatures of transformation may be plausible ascribed to degradation of esters as transition products. Similarly, the decrease in relative contribution of compounds with carbonyl group, especially esters and carboxylic acids, with process temperature was observed in GC-MS results (cf. Fig. 5). At $250{ }^{\circ} \mathrm{C}$ the content of long-chain aliphatic compounds decrease with increasing time of liquefaction. Consequently, it is reliable to suppose that the longer residence time results in a deeper fragmentation of biomass components and higher content of carbonyl compounds. The time does not influence the aliphatic chain length at the temperature of $300{ }^{\circ} \mathrm{C}$ but the slight decrease in $\mathrm{I}_{\mathrm{CO}} / \mathrm{I}_{\mathrm{CH} 2}$ ratio suggests the dehydration of oxygen containing compounds. At 
$350{ }^{\circ} \mathrm{C}$, when compared to $250{ }^{\circ} \mathrm{C}$, the opposite effect is observed. The longer time, the higher fraction of long-chain products is formed. This additionally proves the effect of repolymerization. The longer time causes drop in the content of oxygenates ascribed to the aforementioned dehydration. Overall, the observations noted by FTIR and GC-MS are not contradictory.

\subsection{GPC}

The impact of process variables of cHTL on a molecular mass distribution of bio-oil components was investigated by means of GPC. The relevant chromatograms are presented in Fig. 4. As seen, all the studied bio-oils exhibit the presence of organics of a wide range of molecular masses. They contain numerous organic compounds of a molecular mass that spans two orders of magnitude $\left(10^{2}-10^{4} \mathrm{~g} \mathrm{~mol}^{-1}\right)$. It is understandable in view of a chemical composition of the raw biomass that contains heavy compounds like hydrophobic polypeptides or proteins. The compounds of a lower molecular masses (up to $300 \mathrm{~g} \mathrm{~mol}^{-1}$ ) originate from the cracking reactions. However, depending on the conversion time and temperature, these masses varies substantially. For shorter duration of reaction (7-17 min) the process temperature played crucial role in terms of the molecular mass distribution of bio-oils. All these samples exhibit a relatively sharp peak of a high intensity centered in the range of 350-550 $\mathrm{g} \mathrm{mol}^{-1}$. The most intense maximum of this peak was found for the bio-oil obtained at $250{ }^{\circ} \mathrm{C}$. Additionally, for this sample a few smaller peaks in the range of 860-1050 and 1270-1620 $\mathrm{g} \mathrm{mol}^{-1}$ were observed. In case of the samples obtained at higher temperatures, the intensity of those peaks dropped. This effect could be attributed to the accumulation of heavy intermediates in bio-oil prepared at lower temperatures, e.g. products of degradation of proteins (amino acids), which at higher temperatures undergo depolymerization/cracking reactions. Thus, bio-oils obtained at lower temperatures exhibit higher fractions of compounds 
which have not been cracked deeply. The bio-oils produced at higher temperatures are mixtures characterized by highly diversified molecular mass.

For the oils produced at short reaction times, the increase of conversion temperature caused the effect of reduction of the molecular mass range of bio-oil. This is clearly evidenced by the well-distinguished intensity of the tail that could be seen in the right side of the GPC profile. This in turn suggest that heavier molecules (i.e. proteins, carbohydrates, lipids or algeans) underwent cracking towards lighter molecules with the increase of temperature. In case of longer reaction times at $350^{\circ} \mathrm{C}$ (cf. Fig. 4A'), the temperature has no major impact on the molecular weight distribution, thus all the distributions curves are basically similar. However, the influence of reaction time on the efficiency of the conversion process was noticed at lower temperatures. In case of bio-oil obtained at $250{ }^{\circ} \mathrm{C}$ (cf. Fig. 4B), the increase of reaction time causes a similar trend as the temperature increase at short reaction times. Biooil obtained for 30 min of reaction contains compounds of lower molecular masses. On the other hand, the sample obtained for 7 min of cHTL run represents a relatively higher amount of heavier compounds. The opposite effect was observed in case of bio-oil obtained at $350{ }^{\circ} \mathrm{C}$. Changes in the molecular mass distribution with increasing reaction time can be then most likely assigned to the condensation and repolymerization reactions of lighter components formulating carbonyl compounds (esters or ethers). The heaviest components of bio-oil obtained at $350{ }^{\circ} \mathrm{C}$ exhibit a molecular weight of about $3600 \mathrm{~g} \mathrm{~mol}^{-1}$ for all studied oils.

\subsection{GC-MS}

The composition of the light fraction of bio-oil (i.e. this one of a boiling point $<350{ }^{\circ} \mathrm{C}$ ) was analyzed qualitatively by means of a gas chromatography coupled to mass spectrometry (GCMS). It should be underscored that our settings of GC analysis are relevant exclusively for the compounds containing up to ca. 30 carbon atoms in a molecule due to the limited volatility of higher organics. Based on the experimental data from evaporation of the bio-oil sample, we 
found the volatile fraction of the studied oils (i.e. boiling point up to $350{ }^{\circ} \mathrm{C}$ ) to contribute ca. 35-40 wt. \% of total sample mass. Considering only the peaks of a highest match factor to the reference MS library, there were identified more than 100 compounds. A detailed overview of these compounds as a function of the process temperature was presented in Appendix C. The main groups of the identified compounds are heterocyclic aromatics and alicyclic, higher alkanes, alkenes, amines, phenols, indoles and amides. Such set of groups of organics in biooil produced from low-lipid algae by HTL was reported previously also by others [14,41-47]. In fact, relative contents of groups change slightly what could depend on used algae strain and process variables. For instance, Huang et al. [43] and Shakya et al. [45] reported higher ( $>50 \%$ ) share of nitrogenated compounds, especially N-containing heterocyclic compounds. For the sake of making the discussion more comprehensive, we classified these compounds into eleven groups. This classification was based on the nature of main functional group(s) and the dominant chemical character of the compound as follows:

(1) amines (primary and secondary; aliphatic, aromatic and cyclic e.g. piperidine and its derivatives);

(2) amides (aliphatic/primary);

(3) nitriles (aliphatic and aromatic);

(4) cyclic compounds (lactams, lactones, cyclic imines, imides and cyclic hydrocarbons);

(5) aliphatic hydrocarbons (like alkanes, alkenes and their derivatives);

(6) aromatic compounds (including both aromatic hydrocarbons and heterocyclic compounds exhibiting an aromatic character, i.e. pyrrole);

(7) indoles (indole and its derivatives);

(8) phenols (phenol and its derivatives);

(9) ketones (both aliphatic and cyclic ketones);

(10) other oxygen compounds (e.g. esters, alcohols and carboxylic acids); 
(11) miscellaneous compounds characterized by the presence of various functional groups as well as compounds containing other heteroatoms excepting $\mathrm{N}$ and $\mathrm{O}$; e.g. sulfur. It should be noted that some compounds are of complex structures and could be assigned to at least two groups from the list above. Especially difficult is the classification of some complex cyclic amines and heterocyclic compounds such as lactams. The proposed classification of the identified compounds is an attempt that could help to elucidate the mechanisms of cHTL reactions of bio-oil formation under different process conditions. Moreover it also allows to define the possible applications directions of the bio-oil components in industry or indicates the necessary further downstream processing. The impact of temperature and residence time on the change of bio-oil composition was shown in Fig. 5. As was pointed out in Experimental section, the contributions of particular groups are computed relatively. As seen, the increase in a process temperature resulted in noticeable changes in the group composition of ultimate bio-oils. As the temperature increased, a gradual reduction of the contribution of the most complex compounds group (miscellaneous compounds with higher molecular mass characterized by the presence of various functional groups as well as compounds containing other heteroatoms excepting $\mathrm{N}$ and O; e.g. sulfur) was observed, its share decreased respectively from $22.2 \%$ at $250{ }^{\circ} \mathrm{C}$ to only $5.0 \%$ at $350{ }^{\circ} \mathrm{C}$. This effect can be attributed to the gradual decomposition of primary intermediates via hydrolysis, decarboxylation, dehydration or cracking reactions. The bio-oils obtained at 300 and $350{ }^{\circ} \mathrm{C}$ exhibit the highest shares of the aliphatic hydrocarbons (26.6 and 25.9\%, respectively). Furthermore, the bio-oils obtained at higher temperatures were characterized by the higher contents of oxygenates. For instance the contributions of ketones and phenols at $250{ }^{\circ} \mathrm{C}$ were respectively equal to $3.5 \%$ and $8.6 \%$, respectively, while for $350{ }^{\circ} \mathrm{C}$ the corresponding contributions increased to $11.9 \%$ and $11.5 \%$. The increase in the contributions of phenols and indoles resulting from the higher temperature of the process may be due to their high stability, which is consistent with the results reported 
by other authors $[46,47]$. As the raw material was characterized by the high content of protein, a significant contribution to the bio-oil composition may originate from nitrogen-containing compounds such as amines, amides, nitriles, indoles and lactams. In case of conversion at $350{ }^{\circ} \mathrm{C}$, longer reaction time may entail the occurrence of a secondary re-polymerization between intermediate compounds, which in turn causes the increase in the contribution of the heterocyclic compounds such as lactams to $17.2 \%$ compared to $13.4 \%$ in a sample obtained at $300^{\circ} \mathrm{C}$. This is in line with the previous papers [16,41-43]. The high concentrations of cyclic nitrogen compounds were reported elsewhere $[14,43,45,48]$. The contribution of aromatic compounds was similar notwithstanding the HTL conditions, and ranged between 5.4 and 6.6\%. The other compounds (i.e. oxygenates such as alcohols, esters and carboxylic acids) contributions varied in the range of $0.9-3.0 \%$.

As clearly seen in Fig. 5B and C, changes in the reaction time had brought a noticeable impact on the group composition of the bio-oils. The product obtained at $250{ }^{\circ} \mathrm{C}$ for 17 min exhibits the lowest diversification of the chemical composition. Reasons are not clear, but might be related to relative slower reaction rates of further product degradation and diversification reactions. The group marked as other compounds (the compounds characterized by the highest molecular masses) exhibits higher contribution in case of shorter reaction time. For instance, for $17 \mathrm{~min}$ at $250{ }^{\circ} \mathrm{C}$ the content of other compounds was about $36.7 \%$ while for 30 min at the same temperature it reached $22.2 \%$. These compounds may be intermediates of decomposition of proteins or carbohydrates, which subjected to a longer conversion underwent a further decomposition toward lighter compounds, i.e. lactams or amines. As expected due to that assumption, for longer reaction time the content of this compounds decreased to $22.2 \%$ and the total contribution of amines, amides and nitriles increased from $5.1 \%$ for 17 minutes to $18.0 \%$ for $30 \mathrm{~min}$. In addition, for longer reaction time the contribution of aromatic compounds increased. Furthermore, the high concentration of 
aliphatic hydrocarbons and cyclic compounds, among which lactams brought the largest contribution, was noted.

Notwithstanding the process temperature $\left(250\right.$ or $\left.300{ }^{\circ} \mathrm{C}\right)$, the increasing reaction time lead to decrease in the contribution of the other compounds. The other noteworthy effect is the noticeable increase of the contribution of aliphatic hydrocarbons (from $17.9 \%$ to $26.6 \%$ ), a slight decrease of the content of cyclic compounds (from 16.9\% to 13.4\%) and drop of the aromatic compounds content (from 9.5 to 5.4\%), with increasing reaction time (from 17 to 30 minutes). These changes could be ascribed to gradual decarboxylation of free fatty acids or deamination of amino acids in more harsher conditions towards aliphatic compounds. A decrease of aromatics incl. N-containing aromatics could be due to partial recombination and re-polymerization towards heavier compounds like indole derivatives and PAHs. Those compounds could initiate the formation of solid residue or high boiling-temperature components of bio-oil, as earlier postulated by [5,41,42,48]. A gradual increase in the concentration of ketones with an increase of reaction time was additionally observed. The increase of cyclic ketones in more severe conditions was previously reported by $[42,48]$ and was attributed to rearrangement reactions of furan derivatives intermediates. Interestingly, one may find that the above mentioned findings are in a perfect compliance with the results of FTIR studies.

\subsection{Investigation of mechanisms of biomass decomposition reactions}

The combined consideration of the presented results of FT-IR, GPC and GC-MS analysis allows to postulate the supposed pathways of chemical reactions taking place during the hydrothermal liquefaction of low lipid microalgae. The results presented above have shown that the contribution of each compound group depends strongly on the process variables, particularly temperature. This remains in compliance with previous studies reported by other researchers $[42,45,49]$, who clearly evidenced that HTL temperature had a noticeable impact 
on the molecular composition of bio-oils. It should be kept in mind that the mechanisms governing the formation of bio-oils are extremely complicated. Thus, these changes should be primarily considered starting from the basic biochemical components like lipids, proteins, carbohydrates and fibers. The numerous intermediate compounds formed at the initial stage of the transformation may undergo the secondary reaction either to decompose to lighter compounds or forming more complex structures through the reaction with engagement of other intermediates. Obviously, the rearrangement reactions (i.e. tautomerization) may also occur. Furthermore, due to the presence of mineral matter in the raw biomass, their catalytic activity cannot be excluded. Moreover, it should be emphasized that a number of researchers $[42,50,51]$ suggests a catalytic influence of the reactor construction material (e.g. nickel as a component of stainless steel), what seems to be possible. Indeed, this phenomenon has been also reported as a troublesome effect during scale-up of many other processes.

The postulated mechanisms of decomposition of carbohydrates, lipids and proteins have been proposed formerly by many authors $[10,21,45,48,52,53]$, however the mechanism of protein decomposition through hydrothermal treatment seems to be the most complex and needs to be deepen. Recently, several interesting papers concerning the chemistry of bio-oil formation via hydrothermal treatment have been reported by Gollakota et al. [4] and Kumar et al. [6]. Particularly, the reactions between protein derivatives with intermediates that originate from other groups of components, i.e. carbohydrates and lipids, seem to be crucial for the resultant composition of HTL products, as was earlier pointed out by [48,52,54]. The relatively high content of proteins in the studied species of microalgae (46.3 wt. \%, daf.) was reflected in a high concentration of various nitrogen containing compounds in the resultant bio-oils. Therefore, considering the chemical composition of bio-oil, we made effort to propose the possible pathways of proteins decomposition and the likely subsequent reactions of the formed intermediates. The schematic diagram of the possible routes of transformation of main 
components of microalgae biomass is depicted in Fig. 6. As was mentioned, the obtained samples of bio-oils were viscous, dark-brown, liquids with intense odour. The odor and color of the oils may be caused by the presence of the products of Maillard reactions (occurring between carbohydrates and aminoacids), that exhibits the presence of chromophoric structures responsible for the absorption of the electromagnetic waves in the visible range. As was proved the composition of bio-oil is strongly influenced by the HTL conditions. Depending on the employed process variables, the types of products as well as the contribution of each organics formed by decomposition of proteins may be completely different. According to $[4,16,52]$, primary degradation products of amino acids may be: aromatic hydrocarbons (e.g. toluene and styrene), nitrile (e.g. benzylnitriles), indole and its derivatives (e.g. 3-methyl-1H-indole), phenol and its derivatives (e.g. p-cresol). Indeed, in present study, all of the aforementioned groups of compounds have been identified in final bio-oil, however the quantities of each compound vary with process conditions. The compositions of the HTL bio-oil obtained under different conditions are qualitatively comparable to those reported by [49], but the contributions of the various chemical groups differ.

The increase in indole and phenolic derivatives at higher temperatures and longer reaction times suggests the deeper thermal degradation of proteins. Aromatic compounds may be also formed by secondary reactions of some intermediates, similarly as is the case of carbohydrates and lipids. The vast changes in the properties of water, e.g. ionic product, near the critical point results in the increase in the rate of biomass decomposition reactions. Significantly higher concentration of hydronium $\left(\mathrm{H}_{3} \mathrm{O}^{+}\right)$and hydroxyl $\left(\mathrm{OH}^{-}\right)$ions in water under sub-critical conditions (e.g. approx. 25 times higher at $300{ }^{\circ} \mathrm{C}$ as compared to ambient conditions) cause the water to act as acid/base catalysts, promoting water-involved reactions such as hydrolysis. Highly reactive sub-critical conditions result in the occurrence of 
numerous secondary reactions between intermediates thereby complicating the interpretation of reaction mechanisms. In the present study, at lowest processing temperature $\left(250^{\circ} \mathrm{C}\right)$, the highest contribution of amides (7.6\%) was observed. It may be the result of their formation through aminolysis or ammonolysis reactions occurring in excess of amine or ammonia, respectively, with reactive carboxylic acid derivatives (anhydrides or esters). It also has been observed a scarce fraction of the nitrile, which can be attributed to the occurrence of partial hydrolysis to amides. Both reactions are favored by increased temperature and highly reactive environment.

The increased temperature during hydrothermal liquefaction lead to the decrease in the share of primary amides what may be caused by their direct reduction to amine. Similarly, a highly plausible hypothesis is the hydrolysis of secondary amides, leading to the formation of an amine. It is also possible that the Hofmann rearrangement occurs, where the unsubstituted amides in an alkaline environment undergo rearrangement to primary amines with rapid release of $\mathrm{CO}_{2}$. The studied bio-oils exhibit relatively considerable contributions of lactams, which could be formed by the Beckmann rearrangement. Secondary amines may be also formed by reaction of primary amines with ketones or aldehydes. Similarly, lactams may originate from cyclic amines.

The GC-MS analysis of the bio-oils revealed a relatively high contribution of aromatic heterocyclic compounds such as pyrrole and its derivatives, which are most likely products of protein decomposition. The presence of a heteroatom in the ring causes them to be active in electrophilic substitution reactions. This effect is manifested by the presence of large quantities of various pyrrole derivatives, produced by alkylation. Furthermore, aromatic heterocyclic compounds can be reduced to secondary cyclic amines. The occurrence of this reaction is clearly confirmed by the presence of cyclic aliphatic amine, i.e. pyrrolidine. 
A large share is brought by pyridine and its homologues: methyl-substituted pyridine isomers called picolines, dimethylpyridine called lutidine and collidine, or trimethylpyridine. Pyridine is much less active in electrophilic substitution reactions (ES), which commonly require drastic conditions. It is possible that the lactams are formed from intermediates, that is i.e., hydroxypyridine which more easily undergo the ES reactions compared to pyridine. However, pyridine may undergo reduction to piperidine by hydrogen in the presence of platinum or nickel (present in reactor wall material and detected in mineral matter of the studied biomass). The postulated reaction pathways are in line with previously reported elsewhere mainly based for batch HTL $[5,18,41,42,52]$. Generally, at the beginning of the process biomacromolecules incl. proteins undergo hydrolysis, then decompose deeper mainly via decarboxylation, dehydration or deamination. Subsequently, the formed intermediates can be rearranged via repolymerization, cyclization or condensation. Particularly, the ultimate composition of HTL bio-oil depends on occurring reactions between unstable intermediates derived from a different groups of macromolecules. The course and kinetics of these reactions may rely on process variables, especially reaction temperature and residence time.

\subsection{Bio-oil application}

As was mentioned above, the bio-oil is a mixture of numerous compounds that differ in structure and elemental composition. Notwithstanding the desirable molecular mass range of the noticeable fraction of the bio-oil (i.e. ranging within 7 and 17 carbon atoms that coincides with diesel oil and kerosene composition) [55], the product cannot be utilized directly for fueling the internal combustion engines. This is due to the rigorous standard requirements in terms of chemical composition and physicochemical properties of the fuel biocomponents. The main drawback of as-received bio-oil is the presence of nitrogen- and oxygen-containing compounds. The N-compounds increase the viscosity of fuel $[27,56,57]$ and contribute the emission of $\mathrm{NO}_{\mathrm{x}}$ in exhaust gases. The presence of O-compounds is responsible for the 
decrease in energetic value of fuel. Moreover, it is likely to have an adverse effect on the thermal stability, increases the tendency to polymerization (and formation of resin deposits as well) and diminish the volatility. It is also the reason of higher toxicity and corrosivity of both fuel and exhaust fumes. Thus, the application of bio-oils as a vehicle engines fuels requires additional processing (e.g. hydrogenation) and refining. On the other hand, it should be noted that as-received bio-oil may be an useful source of numerous valuable chemicals that, after the separation and proper purification, could be used in various branches of industry, e.g. for production of pharmaceuticals, cosmetics or dyes, in the so-called fine-chemistry sector.

\section{Conclusions}

The composition of bio-oil obtained from low-lipid microalgae through cHTL may be tailored by adjustment of processing variables, however, some subsequent/parallel effects (i.e. secondary reactions) must be considered while designing the process. The bio-oil produced from Scenedesmus sp. exhibits high content of hydrocarbons and their numerous O- and Nderivatives. Raising the processing temperature to $350{ }^{\circ} \mathrm{C}$ resulted in a noticeable increase in carbon content, slightly higher nitrogen content and pronounced deoxygenation, while hydrogen content remained constant. Despite the high heterogeneity, the bio-oil is a valuable intermediate and may be further utilized either as biofuels component or as a source of numerous value-added chemicals.

\section{Acknowledgements}

This paper was prepared as a part of the statutory activity of the Faculty of Energy and Fuels at the AGH University of Science and Technology under project number 11.11.210.373.

\section{References}

[1] J. Popp, Z. Lakner, M. Harangi-Rákos, M. Fári, The effect of bioenergy expansion: Food, energy, and environment, Renew. Sust. Energ. Rev. 32 (2014) 559-578. 
[2] A. Bahadar, K.M. Bilal, Progress in energy from microalgae: A review, Renew. Sust. Energ. Rev. 27 (2013) 128-148.

[3] A. Dimitriadis, S. Bezergianni, Hydrothermal liquefaction of various biomass and waste feedstocks production: A state of art review, Renew. Sust. Energ. Rev. 68 (2017) 113-125.

[4] A.R.K. Gollakota, N. Kishore, S. Gu, A review on hydrothermal liquefaction of biomass, Renew. Sust. Energ. Rev. 81 (2018) 1378-1392.

[5] Y. Guo, T. Yeh, W. Song, D. Xu, S. Wang, A review of bio-oil production from hydrothermal liquefaction of algae, Renew. Sust. Energ. Rev. 48 (2015) 776-790.

[6] G. Kumar, S. Shobana, W.H. Chen, Q.V. Bach, S.H. Kim, A.E. Atabani, J.S. Chang, A review of thermochemical conversion of microalgal biomass for biofuels: chemistry and processes, Green Chem. 19 (2017) 44-67.

[7] M.S. Vlaskin, N.I. Chernova, S.V. Kiseleva, O.S. Popel, A.Z. Zhuk, Hydrothermal liquefaction of microalgae to produce biofuels: state of the art and future prospects, Therm. Eng. 64 (2017) 627-636.

[8] V. Anikeev, M. Fan, Supercritical fluid technology for energy and environmental applications, Elsevier, Amsterdam, 2014.

[9] A.A. Peterson, F. Vogel, R.P. Lachance, M. Froling, M.J. Antal Jr., J.W. Tester, Thermochemical biofuel production in hydrothermal media: a review of sub- and supercritical water technologies, Energy Environ. Sci. 1 (2008) 32-65.

[10] S.S. Toor, L. Rosendahl, A. Rudolf, Hydrothermal liquefaction of biomass: a review of subcritical water technologies, Energy 36 (2011) 2328-2342.

[11] J. Akhtar, N.A.S. Amin, A review on process conditions for optimum bio-oil yield in hydrothermal liquefaction of biomass, Renew. Sust. Energ. Rev. 40 (2014) 673-687.

[12] K. Prapaiwatcharapan, S. Sunphorka, P. Kuchonthara, K. Kangvansaichol, N. Hinchiranan, Single- and two-step hydrothermal liquefaction of microalgae in a semi- 
continuous reactor: Effect of the operating parameters, Bioresour. Technol. 191 (2015) 426-432.

[13] P.J. Valdez, M.C. Nelson, H.Y. Wang, X.N. Lin, P.E. Savage, Hydrothermal liquefaction of Nannochloropsis sp.: Systematic study of process variables and analysis of the product fractions, Biomass Bioenerg. 46 (2012) 317-331.

[14] D.R. Vardon, B.K. Sharma, G.V. Blazina, K. Rajagopalan, T.J. Strathmann, Thermochemical conversion of raw and defatted algal biomass via hydrothermal liquefaction and slow pyrolysis, Bioresour. Technol. 109 (2012) 178-187.

[15] P. Biller, A.B. Ross, Potential yields and properties of oil from the hydrothermal liquefaction of microalgae with different biochemical content, Bioresour. Technol. 102 (2011) 215-225.

[16] D.L. Barreiro, W. Prins, F. Ronsse, W. Brilman, Hydrothermal liquefaction (HTL) of microalgae for biofuel production: State of the art review and future prospects, Biomass Bioenerg. 53 (2013) 113-127.

[17] J.L. Faeth, P.J. Valdez, P.E. Savage, Hydrothermal liquefaction of Nannochloropsis sp. to produce biocrude, Energ. Fuels 27 (2013) 1391-1398.

[18] C. Tian, B. Li, Z. Liu, Y. Zhang, H. Lu, Hydrothermal liquefaction for algal biorefinery: A critical review, Renew. Sust. Energ. Rev. 38 (2014) 933-950.

[19] D. Xu, P.E. Savage, Effect of temperature, water loading, and Ru/C catalyst on water insoluble and water-soluble biocrude fractions from hydrothermal liquefaction of algae, Bioresour. Technol. 239 (2017) 1-6.

[20] B. Zhang, M. von Keitz, K. Valentas, Thermochemical liquefaction of high-diversity grassland perennials, J. Anal. Appl. Pyrolysis 84 (2009) 18-24. 
[21] Y. Chen, Y. Wu, D. Hua, C. Li, M.P. Harold, J. Wang, M. Yang, Thermochemical conversion of low-lipid microalgae for the production of liquid fuels: challenges and opportunities, RSC Adv. 5 (2015) 18673-18701.

[22] U. Jena, K.C. Das, J.R. Kastner, Comparison of the effects of $\mathrm{Na}_{2} \mathrm{CO}_{3}, \mathrm{Ca}_{3}\left(\mathrm{PO}_{4}\right)_{2}$, and $\mathrm{NiO}$ catalysts on the thermochemical liquefaction of microalga Spirulina platensis, Appl. Energy 98 (2012) 368-375.

[23] D.L. Barreiro, S. Riede, U. Hornung, A. Kruse, W. Prins, Hydrothermal liquefaction of microalgae: Effect on the product yields of the addition of an organic solvent to separate the aqueous phase and the biocrude oil, Algal Res. 12 (2015) 206-212.

[24] P.J. Valdez, J.G. Dickinson, P.E. Savage, Characterization of product fractions from hydrothermal liquefaction of Nannochloropsis sp. and the influence of solvents; Energ. Fuels 25 (2011) 3235-3243.

[25] D.C. Elliott, T.R. Hart, A.J. Schmidt, G.G. Neuenschwander, L.J. Rotness, M.V. Olarte, A.H. Zacher, K.O. Albrecht, R.T. Hallen, J.E. Holladay, Process development for hydrothermal liquefaction of algae feedstocks in a continuous-flow reactor, Algal Res. 2 (2013) 445-454.

[26] C. Jazrawi, P. Biller, A.B. Ross, A. Montoya, T. Maschmeyer, B.S. Haynes, Pilot plant testing of continuous hydrothermal liquefaction of microalgae, Algal Res. 2 (2013) 268277.

[27] A. Lee, D. Lewis, T. Kalaitzidis, P. Ashman, Technical issues in the large scale hydrothermal liquefaction of the microalagal biomass to biocrude, Curr. Opin. Biotech. 38 (2016) 85-89.

[28] B. Patel, K. Hellgardt, Hydrothermal upgrading of algae paste in a continuous flow reactor, Bioresour. Technol. 191 (2015) 460-468. 
[29] R. Garofalo, Algae and aquatic biomass for a sustainable production of $2^{\text {nd }}$ generation biofuels. AquaFUELs - Taxonomy, Biology and Biotechnology 2009, 92-96.

[30] L. Garcia Alba, C. Torri, C. Samorì, J. van der Spek, D. Fabbri, S.R.A. Kersten, D.W.F. Brilman, Hydrothermal treatment (HTT) of microalgae: evaluation of the process as conversion method in an algae biorefinery concept. Energ. Fuels 26 (2012) 642-657.

[31] D.B. Jones, Factors for converting percentages of nitrogen in foods and feeds into percentages of proteins. Circular 183 Department of Agriculture (1931) 1-21.

[32] A.E. Harman-Ware, J.R. Ferrell III, Characterization of catalytic fast pyrolysis oils: The importance of solvent selection for analytical method development, J. Anal. Appl. Pyrolysis 132 (2018) 190-199.

[33] M. Giordano, A. Norici, S. Ratti, J.A. Raven, Role of sulfur for algae: acquisition, metabolism, ecology and evolution, in: R. Hell, C. Dahl, D.B. Knaff, Th. Leustek (Eds.), Sulfur Metabolism in Phototrophic Organism, Springer, 2008, 397-415.

[34] J.L. Faeth, P.E. Savage, Effects of processing conditions on biocrude yields from fast hydrothermal liquefaction of microalgae, Bioresour. Technol. 206 (2016) 290-293.

[35] D.W.F. Brilman, N. Drabik, M. Wądrzyk, Hydrothermal co-liquefaction of microalgae, wood, and sugar beet pulp, Biomass Conv. Bioref. 7 (2017) 445-454.

[36] T.M. Brown, P. Duan, P.E. Savage, Hydrothermal liquefaction and gasification of Nannochloropsis sp., Energ. Fuels 24 (2010) 3639-3646.

[37] A.B. Ross, P. Biller, M.L. Kubacki, H. Li, A. Lea-Langton, J.M. Jones, Hydrothermal processing of microalgae using alkali and organic acids, Fuel 89 (2010) 2234-2243.

[38] C. Torri, D. Fabbri, L. Garcia-Alba, D.W.F. Brilman, Upgrading of oils derived from hydrothermal treatment of microalgae by catalytic cracking over H-ZSM-5: A comparative Py-GC-MS study, J. Anal. Appl. Pyrolysis 101 (2013) 28-34. 
[39] N. Pasadakis, G. Livanos, M. Zervakis, Deconvolving the absorbance of methyl and methylene groups in the FT-IR $3000-2800 \mathrm{~cm}^{-1}$ band of petroleum fractions, Trends. Appl. Spectrosc. 10 (2013) 25-35.

[40] J. Pironon, R. Thiery, M. Ayt Ougougdal, S. Teinturier, G. Beaudoin, F. Walgenwitz, FT-IR measurements of petroleum fluid inclusions: methane, n-alkanes and carbon dioxide quantitative analysis, Geofluids 1 (2001) 2-10.

[41] Y. Chen, N. Zhao, Y. Wu, K. Wu, X. Wu, J. Liu, M. Yanh, Distributions of organic compounds to the products from hydrothermal liquefaction of microalgae, Environ. Prog. Sustain. Energy 36 (2017) 259-268.

[42] C. Gai, Y. Zhang, W-T Chen, P. Zhang, Y. Dong, An investigation of reaction pathways of hydrothermal liquefaction using Chlorella pyrenoidosa and Spirulina platensis, Energy Convers. Manag. 96 (2015) 330-339.

[43] Y. Huang, Y. Chen, J. Xie, H. Liu, X. Yin, C. Wu, Bio-oil production from hydrothermal liquefaction of high-protein high-ash microalgae including wild Cyanobacteria sp. and cultivated Bacillariophyta sp., Fuel 183 (2016) 9-19.

[44] S. Liang, L. Wei, M.L. Passero, K. Feris, A.G. McDonald, Hydrothermal liquefaction of laboratory cultivated and commercial algal biomass into crude bio-oil, Environ. Prog. Sustain. Energy 36 (2017) 781-787.

[45] R. Shakya, S. Adhikari, R. Mahadevan, S.R. Shanmugam, H. Nam, E.B. Hassan, T.A. Dempster, Influence of biochemical composition during hydrothermal liquefaction of algae on product yields and fuel properties, Bioresour. Technol. 243 (2017) 1112-1120.

[46] W. Song, S. Wang, Y. Guo, D. Xu, Bio-oil production from hydrothermal liquefaction of waste Cyanophyta biomass: Influence of process variables and their interactions on the product distributions, Int. J. Hydrogen Energy 42 (2017) 20361-20374. 
[47] C. Torri, D.L. Barreiro, R. Conti, D. Fabbri, W. Brilman, Fast procedure for the analysis of hydrothermal liquefaction biocrude with stepwise Py-GC-MS and data interpretation assisted by means of non-negative matrix factorization, Energ. Fuels 30 (2016) 1135-1144.

[48] W. Yang, X. Li, Z. Li, Ch. Tong, L. Feng, Understanding low-lipid algae hydrothermal liquefaction characteristics and pathways through hydrothermal liquefaction of algal major components: Crude polysaccharides, crude proteins and their binary mixtures, Bioresour. Technol. 196 (2015) 99-108.

[49] C. Torri, L. Garcia Alba, C. Samori, D. Fabbri, D.W.F. Brilman, Hydrothermal treatment (HTT) of microalgae: detailed molecular characterization of HTT oil in view of HTT mechanism elucidation, Energ. Fuels 26 (2012) 658-671.

[50] M. Faisal, Catalytic effect of different reactor materials under subcritical water conditions: decarboxylation of cysteic acid into taurine, IOP Conf. Ser.: Mater. Sci. Eng. $334(2018) 1-7$.

[51] P.G. Maiella, T.B. Brill, Spectroscopy of hydrothermal reactions. 10. Evidence of wall effects in decarboxylation kinetics of $1.00 \mathrm{~m} \mathrm{HCO} 2 \mathrm{X}(\mathrm{X}=\mathrm{H}, \mathrm{Na})$ at $280-330{ }^{\circ} \mathrm{C}$ and 275 bar, J. Phys. Chem. A 102 (1998) 5886-5891.

[52] S.M. Changi, J.L. Faeth, N. Mo, P.E. Savage, Hydrothermal reactions of biomolecules relevant for microalgae liquefaction, Ind. Eng. Chem. Res 54 (2015) 11733-11758.

[53] G. Teri, L. Luo, P.E. Savage, Hydrothermal treatment of protein, polysaccharide and lipids alone and in mixtures. Energ. Fuels 28 (2014) 7501-7509.

[54] A.A. Peterson, R.P. Lachance, J.W. Tester, Kinetic evidence of the Maillard reaction in hydrothermal biomass processing: glucose-glycine interactions in high-temperature, highpressure water, Ind. Eng. Chem. Res. 49 (2010) 2107-2117. 
[55] S. Parkash, Petroleum fuels manufacturing handbook: including specialty products and sustainable manufacturing techniques, , 1st ed., 2010.The McGraw-Hill Companies, Inc., New York, 2010.

[56] G. Knothe, K.R. Steidley, Kinematic viscosity of biodiesel fuel components and related compounds. Influence of compound structure and comparison to petrodiesel fuel components, Fuel 84 (2005) 1059-1065.

[57] P.Y. Hsieh, T.J. Bruno, A perspective on the origin of lubricity in petroleum distillate motor fuels, Fuel Process. Technol. 129 (2015) 52-60. 


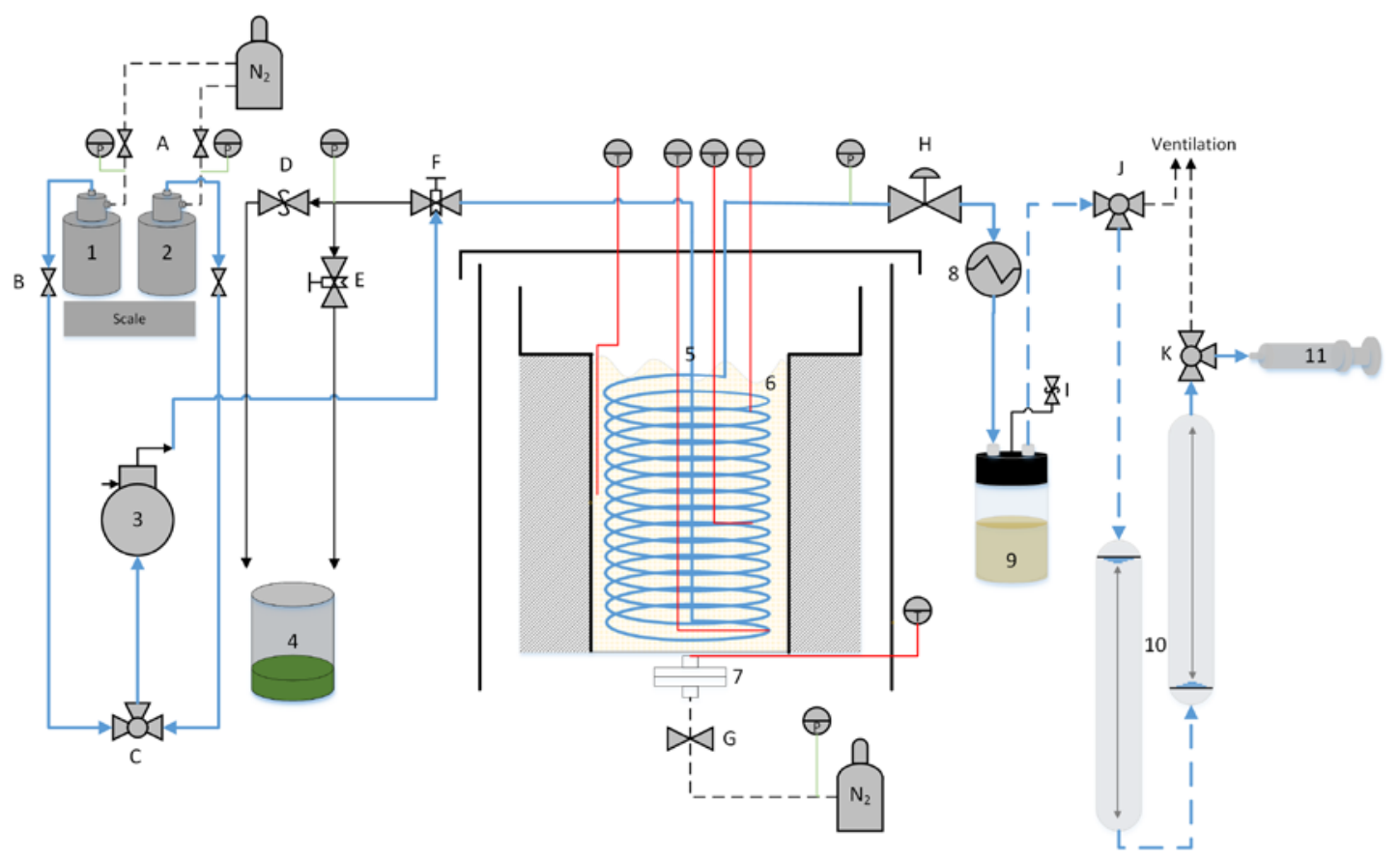

1-algal slurry vessel, 2-demineralized water vessel, 3-reciprocal pump, 4-waste vessel, 5-fluidized sand bed,

6-coil reactor, 7-gas pre-heater, 8-tube-in-tube co-current water cooler, 9-liquid product collector, 10-gas product collector, 11-gas sampling syringe

A-valve to control pressure in feedstock vessel, B-valve to control feedstock flow rate into pump, C-valve to set pump feed (water or algal slurry), D-safety release valve, E-valve for purging air from pump, F-valve for separating the pump and reactor coil from each other, G-valve to control bed fluidization, $\mathrm{H}$-main valve to control operation pressure in reactor zone, I-safety release valve, $\mathrm{J}$-gas valve, $\mathrm{K}$-gas sampling valve

Fig. 1. Scheme of setup used for cHTL experiments.
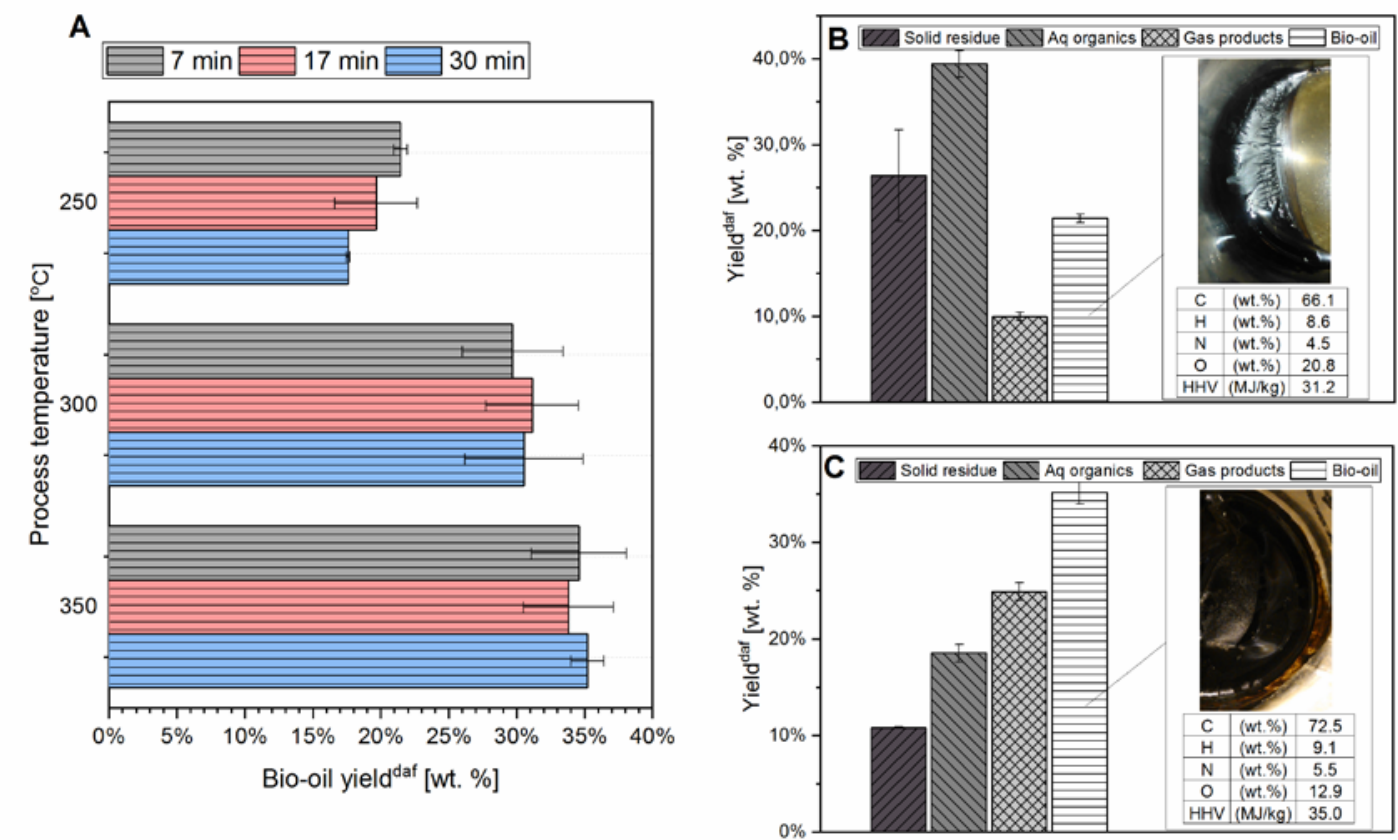

Fig. 2. Products yield distribution, elemental analysis and HHV of cHTL bio-oils obtained under the boundary time-temperature conditions: at $250{ }^{\circ} \mathrm{C}$ for $7 \mathrm{~min}(\mathrm{~A})$, at $350{ }^{\circ} \mathrm{C}$ for 30 min (B), insets: photographs of produced bio-oils. 

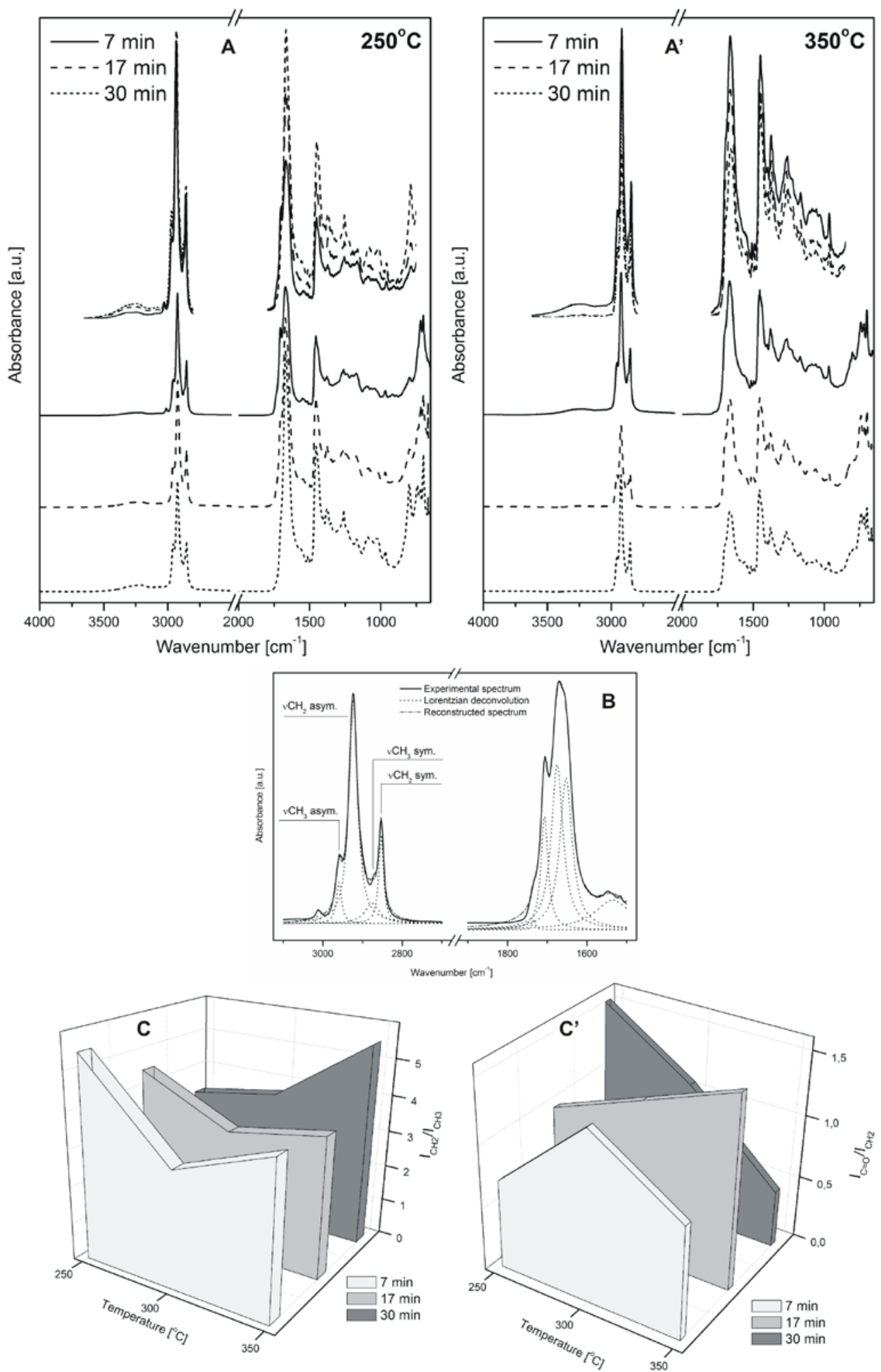

Fig. 3. ATR FT-IR spectra of bio-oils obtained by cHTL of microalgae biomass at $250{ }^{\circ} \mathrm{C}$ and $350^{\circ} \mathrm{C}$ for 7, 17 and $30 \mathrm{~min}$ (A and A', respectively), exemplary Lorentzian deconvolution of aliphatic $\mathrm{C}-\mathrm{H}$ bands and $\mathrm{C}=\mathrm{O}$ modes $(\mathrm{B})$ relative intensities of $\mathrm{CH}_{2}$ and $\mathrm{CH}_{3}$ modes (2923 and $2955 \mathrm{~cm}^{-1}$, respectively) indicative of the relative lengths of aliphatic carbon chains (C) and respective $\mathrm{I}_{\mathrm{C}=\mathrm{O}} / \mathrm{I}_{\mathrm{CH} 2}$ ratios (1702 and $2923 \mathrm{~cm}^{-1}$, respectively) as a relative contents of carbonyl compounds (C'). 

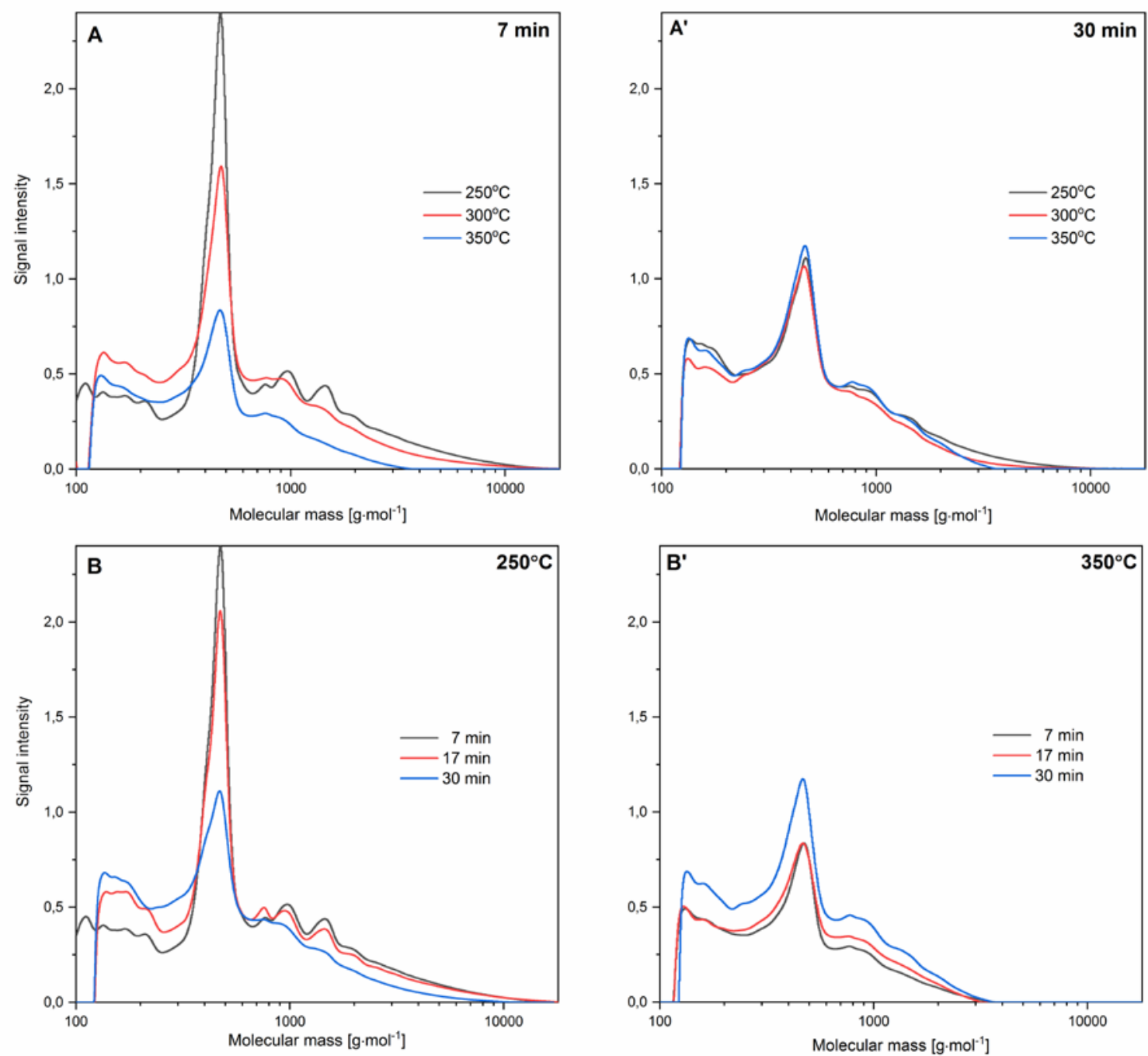

Fig. 4. Molecular mass distributions of cHTL bio-oils obtained at different temperatures for 7 and 30 min (A, A', respectively) and for different reaction times at 250 and $350{ }^{\circ} \mathrm{C}$ (B, B', respectively), determined by GPC. 

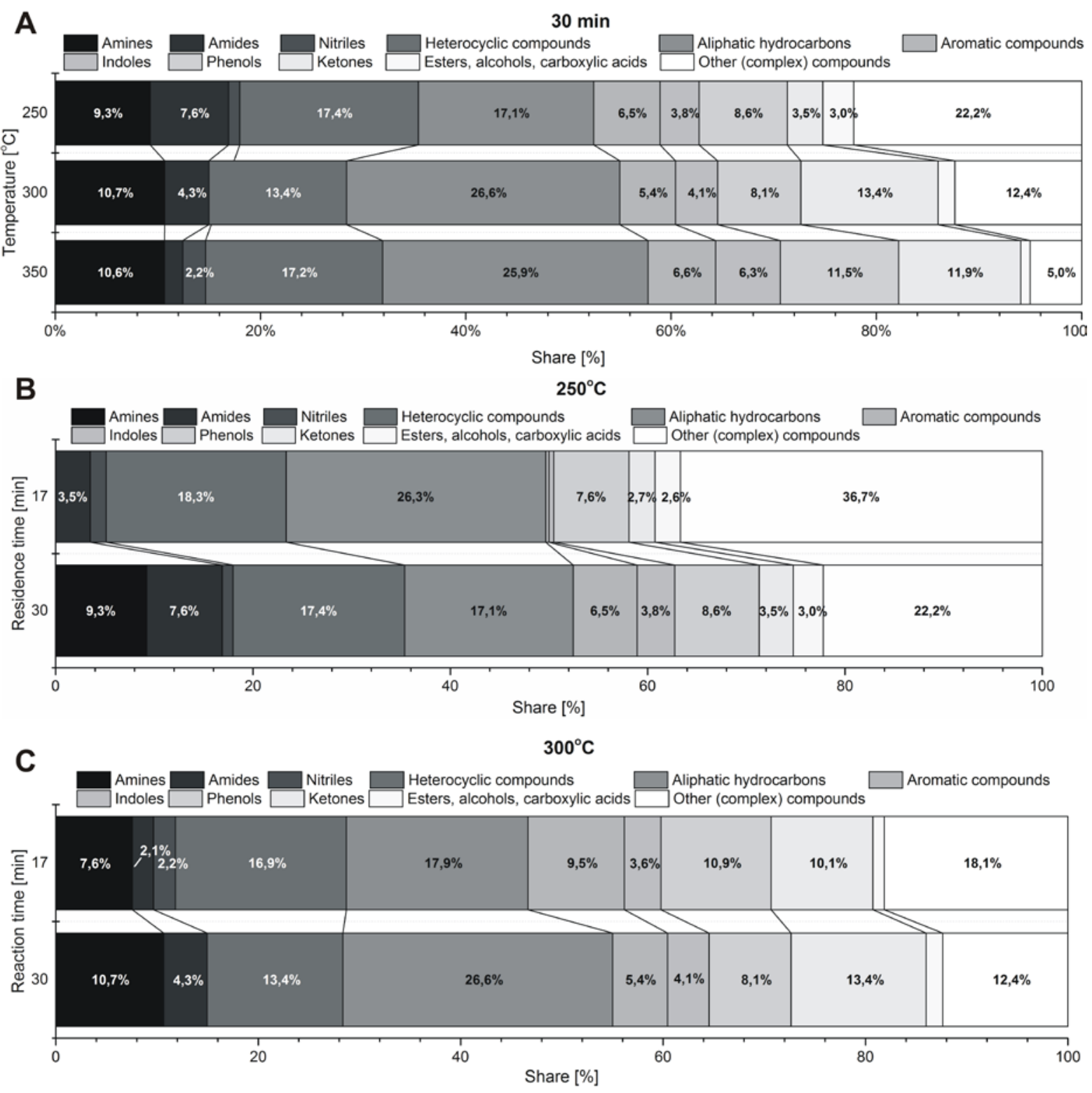

Fig. 5. Effect of parameters of cHTL process on the contributions of organic compounds groups identified in bio-oils: impact of temperature for $30 \mathrm{~min}$ experiments (A) and influence of reaction time for runs performed at $250{ }^{\circ} \mathrm{C}(\mathrm{B})$ and $300^{\circ} \mathrm{C}(\mathrm{C})$. 


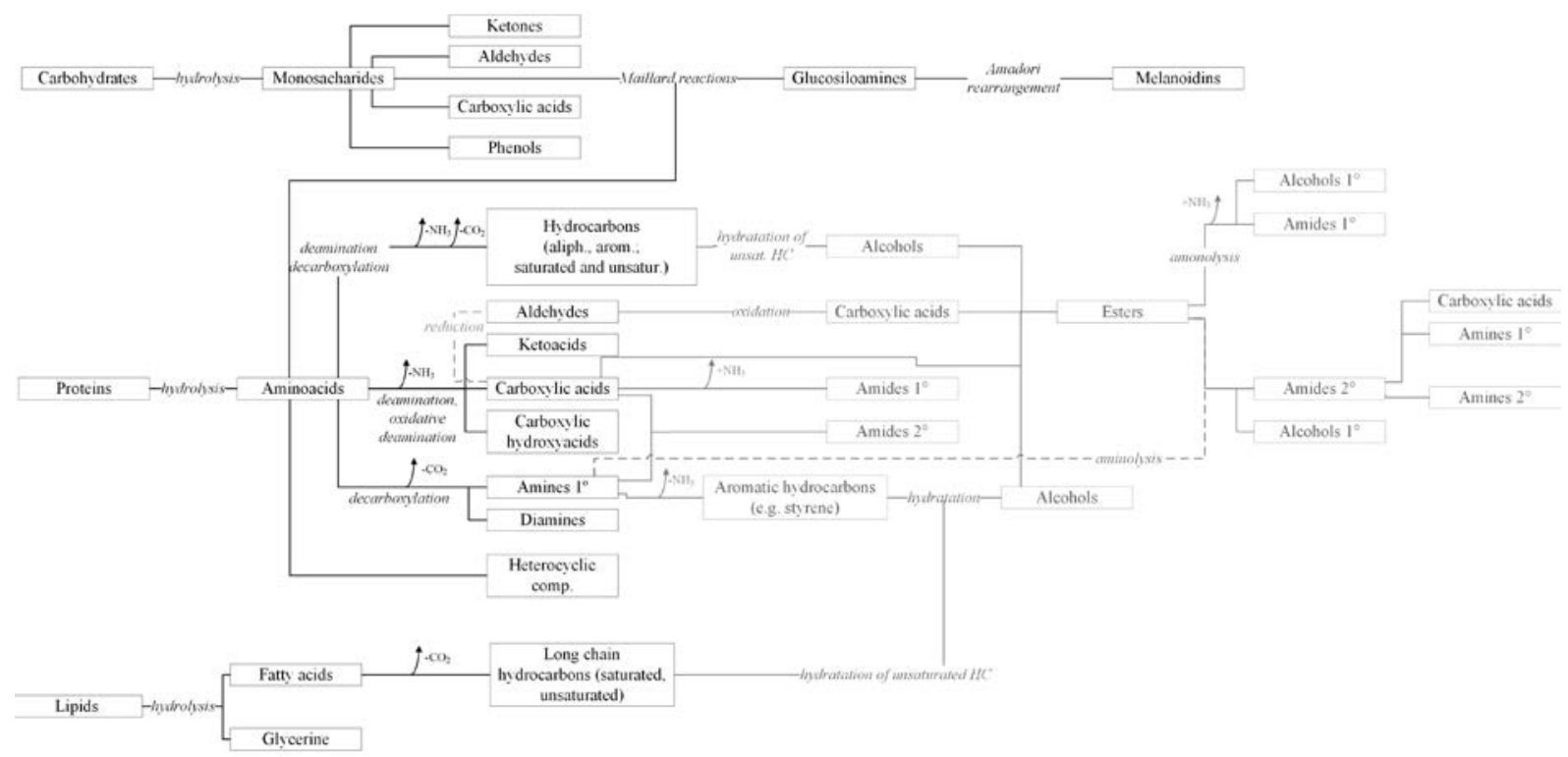

Fig. 6. Postulated pathways of decomposition of main biochemical components of studied biomass during cHTL of Scenedesmus sp. (black and grey paths mean primary and secondary reactions, respectively).

Table 1. Composition of Scenedesmus sp. feedstock

\begin{tabular}{|c|c|c|c|c|c|c|}
\hline \multirow{2}{*}{\multicolumn{2}{|c|}{$\begin{array}{c}\text { Proximate analysis } \\
\text { [wt. \%] }\end{array}$}} & \multirow{2}{*}{\multicolumn{2}{|c|}{$\begin{array}{c}\text { Biochemical composition } \\
\text { [wt. \%] daf }\end{array}$}} & \multicolumn{3}{|c|}{ Ultimate analysis } \\
\hline & & & & Element & [wt. \%] ${ }^{\mathrm{d}}$ & [wt. \%] daf \\
\hline Water $^{\mathrm{a}}$ & 94.35 & & & $\mathrm{C}$ & 33.4 & 56.4 \\
\hline Dry residue ${ }^{\mathrm{a}}$ & 5.65 & Lipid & 5.6 & $\mathrm{H}$ & 4.7 & 7.9 \\
\hline $\operatorname{Ash}^{\mathrm{d}}$ & 40.80 & Protein & 46.3 & $\mathrm{~N}$ & 4.4 & 7.4 \\
\hline Organic matter ${ }^{\mathrm{d}}$ & 59.20 & Fiber \& carbohydrates & $48.1^{\mathrm{b}}$ & S & 0.2 & 0.4 \\
\hline $\mathrm{HHV}^{\mathrm{d}}$ & $15.7 \mathrm{MJ} / \mathrm{kg}$ & & & $\mathrm{O}$ & $16.5^{\mathrm{c}}$ & $27.9^{c}$ \\
\hline
\end{tabular}

${ }^{\mathrm{a}}$ Determined for as-received feedstock slurry; ${ }^{\mathrm{b}}$ Calculated as: Fiber \& Carbohydr. $=100 \%-$ Lipid $\%-$ Protein $\%$; ${ }^{\mathrm{c}}$ Calculated as: [O] $=$ $100 \%-[\mathrm{C}]-[\mathrm{H}]-[\mathrm{N}]-[\mathrm{S}] ;{ }^{\mathrm{d}}$ Calculated on dry matter; ${ }^{\text {daf }}$ Calculated on dry, ash free matter. 